\title{
Congestion of LV distribution networks by household battery energy storage systems utilized for FCR, aFRR and market trading
}

Citation for published version (APA):

Roos, M. H., \& Holthuizen, B. (2018). Congestion of LV distribution networks by household battery energy storage systems utilized for FCR, aFRR and market trading. In 53rd International Universities Power Engineering Conference 4th-7th September 2018, Glasgow, Scotland [8541879] Institute of Electrical and Electronics Engineers. https://doi.org/10.1109/UPEC.2018.8541879

DOI:

10.1109/UPEC.2018.8541879

Document status and date:

Published: 20/11/2018

Document Version:

Accepted manuscript including changes made at the peer-review stage

Please check the document version of this publication:

- A submitted manuscript is the version of the article upon submission and before peer-review. There can be important differences between the submitted version and the official published version of record. People interested in the research are advised to contact the author for the final version of the publication, or visit the $\mathrm{DOI}$ to the publisher's website.

- The final author version and the galley proof are versions of the publication after peer review.

- The final published version features the final layout of the paper including the volume, issue and page numbers.

Link to publication

\footnotetext{
General rights

- You may freely distribute the URL identifying the publication in the public portal. follow below link for the End User Agreement:

www.tue.nl/taverne

\section{Take down policy}

If you believe that this document breaches copyright please contact us at:

openaccess@tue.nl

providing details and we will investigate your claim.
}

Copyright and moral rights for the publications made accessible in the public portal are retained by the authors and/or other copyright owners and it is a condition of accessing publications that users recognise and abide by the legal requirements associated with these rights.

- Users may download and print one copy of any publication from the public portal for the purpose of private study or research.

- You may not further distribute the material or use it for any profit-making activity or commercial gain

If the publication is distributed under the terms of Article 25fa of the Dutch Copyright Act, indicated by the "Taverne" license above, please 


\section{Congestion of LV Distribution Networks by Household Battery Energy Storage Systems utilized for FCR, aFRR and Market Trading}

\author{
Martijn Roos \\ Electrical Engineering \\ Eindhoven University of Technology \\ Eindhoven, the Netherlands \\ m.h.roos@tue.nl
}

\author{
Bart Holthuizen \\ Asset Management \\ Enexis \\ 's-Hertogenbosch, the Netherlands \\ b.j.d.holthuizen@students.uu.nl
}

\begin{abstract}
An increasing number of households have distributed generation (DG), while in many countries netting arrangements are disappearing. Therefore, consumers are driven to increase self-consumption with household battery energy storage systems (HBESS). To maximize benefits, HBESS may be utilized for frequency control reserve (FCR), automated frequency restoration reserve (aFRR) and trading on the day-ahead market in the future. The potentially high simultaneity factor and power rating of HBESS could cause overloading and voltage magnitude problems in distribution networks. Distribution network operators (DNOs) currently do not take market trading HBESS into account in low voltage ( $\mathrm{LV})$ network planning. This paper proposes a methodology which enables DNOs to determine the impact of HBESS on the distribution network. The methodology enables analysis of HBESS utilized for FCR, aFRR and trading on the day-ahead markets with minimum input data required. The methodology is demonstrated for each market and two HBESS penetration rates in four real $\mathrm{LV}$ distribution networks.
\end{abstract}

Index Terms-Energy storage; market trading; network congestion; self-consumption

\section{INTRODUCTION}

Within distribution networks a trend is visible towards the integration of more distributed generation (DG), such as household photovoltaics (PV). Without present netting arrangements, consumers are economically driven to increase self-consumption of generated energy. A household battery energy storage system (HBESS) is one of the foremost ways to increase the self-consumption for consumers [1]. Increasing the self-consumption of households will decrease the loading of the low voltage (LV) distribution networks, since part of the energy used by the household is locally generated, stored and utilized. However in the near future HBESS could be utilized for frequency control reserve (FCR), automated frequency restoration reserve (aFRR) and trading on day-ahead markets [2]. The FCR is utilized when the network frequency deviates from nominal. The capacity for FCR is usually procured via

This work has received funding from the European Union's Horizon 2020 research and innovation program under grant agreement No 773717 .

978-1-5386-2910-9/18/\$31.00 (C) 2018 IEEE bilateral contracts with operators of power plants or aggregators of DG. The aFRR capacity is utilized when frequency disturbances are longer than the predetermined timescale of FCR. This capacity can be obtained by bilateral contracts or via an auction-based market. On the day-ahead market consumers and suppliers can trade energy, every day the market clearing price and volume are determined depending on the bids of that day [3].

Due to the relatively high power rating of HBESS compared to other household appliances, HBESS greatly impacts the power flow in LV distribution networks. Additionally, when HBESS in an network is utilized for the same application (e.g. FCR, aFRR or day-ahead market) the (dis)charging can have a high simultaneity factor. Charging of HBESS increases the top-down power flow, while discharging of HBESS increases the bottom-up power flow in the network. This potentially causes large LV congestion issues which should be analyzed by distribution network operators (DNOs) in LV network planning scenarios.

Existing methods to analyze the behavior of HBESS for multiple applications usually requires a vast amount of input data (e.g. detailed data forecasts, aggregator models) [4], [5]. For network planning this data may not always be available and the level of detail is often not required. A method should be able to give an indication of the severity and location of overloading network components and voltage magnitude problems, while requiring minimal input data.

This paper proposes a methodology to determine the impact of HBESS utilized for FCR, aFRR and trading on the day-ahead market on distribution networks, and identify the location and severity of overloading and voltage magnitude problems. The contributions of this paper are:

1) A methodology to determine the impact of HBESS utilized for FCR, aFRR and trading on the day-ahead market using minimal input data.

2) Analysis of the impact of HBESS on network congestion in study cases of four real LV distribution networks.

In the next section the methodology is described, in section III the study cases are presented, section IV shows and 
discusses the results of the study cases, and conclusions are given in section VI.

\section{Methodology}

To analyze congestion and voltage magnitude problems in a network, the methodology proposed in this section generates HBESS (dis)charging profiles which are combined with demand profiles of household appliances to create household demand profiles. The household demand profiles are utilized for load flow calculations to determine the congestion problems in networks. Therefore, this methodology can be easily utilized for network planning by DNOs.

\section{A. Selection of HDLG and $L D H G$ days}

As discussed before, HBESS can cause congestion issues by increasing the top-down or bottom-up power flow. The proposed method generates two HBESS (dis)charging profiles for each considered HBESS application. The first profile represents a day with the highest expected load demand and lowest DG generation (HDLG), while the second profile represents a day with the lowest expected load demand and highest DG generation (LDHG). During the HDLG day the highest topdown power flow occurs in the network, while during the LDHG day the highest bottom-up power flow occurs.

The FCR, aFRR and day-ahead market signals should also be chosen for the HDLG and LDHG days. For the FCR, the frequency signals of the day with the largest frequency deviations are utilized. For the aFRR and day-ahead market, two sets of price signals are utilized. The set for the HDLG day has the lowest expected prices during the demand peak of the day. The set for the LDHG day has the highest expected prices during the generation peak of the day.

Usually the HDLG day will occur during winter due to the low solar irradiation, and high household heating and lighting demand. The LDHG day usually occurs during spring or summer due to the high solar irradiation, and low heating and lighting demand. Naturally this depends on factors such as the geographical location, type of DG and consumer behavior.

\section{B. Generation of HBESS profiles}

The HBESS (dis)charging profiles are determined by minimizing the energy costs and maximizing benefits from HBESS on household-level over the HDLG and LDHG days. The objective function which should be minimized is shown in equation $1 \mathrm{a}$.

$$
\begin{aligned}
\min & \sum_{t=1}^{T}(\alpha(t) C+\beta(t) F)\left(P_{\text {Load }}(t)-P_{D G}(t)-P_{H B E S S}(t)\right) \\
& \quad-\delta(t) M(t) P_{H B E S S}(t)
\end{aligned}
$$

where:

$$
\begin{gathered}
\alpha(t)= \begin{cases}1 & \text { if } P_{\text {Load }}>P_{D G}+P_{\text {HBESS }} \\
0 & \text { otherwise }\end{cases} \\
\beta(t)= \begin{cases}1 & \text { if } P_{\text {Load }} \\
0 & \text { otherwise }\end{cases}
\end{gathered}
$$

Where $T$ are the number of time steps of a single day, $C$ is the energy cost, $F$ is the feed-in tariff, $P_{D G}(t)$ is the power output of household DG (e.g. PV), $P_{\text {load }}(t)$ is the power demand of the local load, $M(t)$ is the FCR, aFRR or market price, and $P_{H B E S S}$ is the power injection of the local HBESS. The control variable $P_{H B E S S}$ can be controlled as described in the remainder of this subsection to minimize the objective function 1a. To minimize the objective function the energy cost, feed-in tariff, price $M(t)$, DG generation profile and local load demand profile are required on HDLG and LDHG days.

1) FCR: To participate in FCR, a predefined part of the power and energy capacity of the HBESS is reserved. The output power of the HBESS is therefore described by equation 2 .

$$
P_{H B E S S}(t)=P_{M}(t)+P_{S C}(t)
$$

The share of the HBESS power capacity utilized for FCR $(\delta(t))$ is described by equation 3 .

$$
\delta(t)=\frac{P_{M}(t)}{P_{H B E S S}(t)}
$$

Where $P_{M}$ is part of the HBESS which is regulated by the primary control and $P_{S C}$ is part of the HBESS which can be utilized to increase self-consumption of DG generation.

The output power $P_{M}$ is regulated according to the network frequency and frequency droop parameter. If the frequency is below the nominal frequency $f_{n o m}$ the HBESS injects power and when the frequency is above nominal frequency the HBESS absorbs power. The control of the output power is therefore described by equation 4 .

$$
P_{M}(t)=k\left(f_{\text {nom }}-f(t)\right)
$$

Where $f$ is the network frequency at time $t$, and $k$ is the frequency droop parameter.

The remaining part can be utilized by the consumer to increase self-consumption of DG. However since $P_{S C}$ should not decrease $P_{M}$ below the requested (injected or absorbed) power by FCR, $P_{S C}$ is zero when $P_{M}$ and $P_{S C}$ have opposite signs. This is described by equation 5 , where $P_{n e t}(t)=$ $P_{\text {load }}(t)-P_{D G}(t)$.

$$
P_{S C}(t)= \begin{cases}P_{n e t}(t) & \text { if } f(t)<f_{n o m} \cap P_{n e t}(t)>0 \\ P_{n e t}(t) & \text { if } f(t)>f_{\text {nom }} \cap P_{\text {net }}(t)<0 \\ 0 & \text { otherwise }\end{cases}
$$

The total active power injection or absorption $P_{H B E S S}$ is constrained by the power rating of the HBESS. This also constrains power $P_{M}$ and $P_{S C}$ according to the share which is reserved for FCR.

To determine the demand profile for HBESS utilized for FCR the reserved power and energy capacity, expected frequency signals on HDLG and LDHG days, and frequency droop parameters are required. 
2) aFRR and day-ahead market: When utilized for aFRR the HBESS switches between increasing DG self-consumption and aFRR at every time interval $t$. For trading on the dayahead market the HBESS swiches between increasing selfconsumption and the day-ahead market. The HBESS switches depending on the benefits of each application. The HBESS is assumed to discharge when $M(t)$ is higher than the difference between the sum of the consumer energy price $C$ and the (unidirectional) losses $l$, and the feed-in tariff $F$. The HBESS is assumed to charge when $M(t)$ is lower than the difference between the supplier share of the consumer energy price $C_{E}$ and the unidirectional losses. When the market price is between these two values, the HBESS is operated to increase the self-consumption. The operation of HBESS on the secondary reserve and day-ahead markets are described by equation 6 .

$$
P_{B E S S}(t)= \begin{cases}>0 & \text { if } M(t)>C+l-F \\ <0 & \text { if } M(t)<C_{E}-l \\ P_{n e t}(t) & \text { otherwise }\end{cases}
$$

Since the HBESS switches between aFRR or day-ahead market trading and increasing self-consumption, the share of the HBESS utilized for aFRR or day-ahead market trading is either zero or one as described by equation 7 .

$$
\delta(t)= \begin{cases}1 & \text { if } M(t)>C+l-F \\ 1 & \text { if } M(t)<C_{E}-l \\ 0 & \text { otherwise }\end{cases}
$$

To determine the demand profile of HBESS utilized for aFRR or day-ahead market trading, assumptions should be made for the losses of the energy storage and consumer energy price.

\section{Household and network model}

To simulate network loading and voltage magnitude, loadflow calculations are performed using Phase to Phase Vision [6]. The households are modeled as constant power loads connected to a PQ bus, the primary side of the medium to low voltage transformers is connected to a slack bus and the cables are modeled as PI equivalent impedance.

The household demand is equal to the total power absorbed by the household at every time instant. Therefore the household demand $P_{H H}$ is described by equation 8 .

$$
P_{H H}(t)=P_{\text {load }}(t)-P_{D G}(t)-P_{H B E S S}(t)
$$

After loadflow calculations, the required cable and transformer upgrades can be determined for each study case. Both cables and transformers are assumed to be upgraded when they are overloaded at any time of the day in the study cases. When voltage deviation problems occur, cables are replaced until the voltage problems are mitigated. In order to give an indication of the potential network upgrade costs, average costs of $€ 80 / \mathrm{m}$ cable and $€ 20.000$ per transformer are used [7].

\section{StUdy CASES}

To demonstrate the methodology described in section II and give an indication of the possible impact of HBESS, study cases of four real networks in the Netherlands are analyzed. Depending on the study case, a number of households in the networks have PV, a battery electric vehicle (BEV) and HBESS. In each study case the network loading, voltage magnitude and required network upgrades are determined.

\section{A. Networks and devices}

Typical LV networks in the Netherlands have been identified by [8]. The networks are categorized as dense urban, urban, semi-urban and rural. Networks Schilderswijk (dense urban), Nootdorp (urban), Westbroekpark (semi-urban) and Exel (rural) are analyzed to study a variety of networks which supply $669,143,399$ and $51 \mathrm{LV}$ consumers respectively.

Seven study cases are analyzed for each network. The first study case is a base case in which households have domestic load with the addition of PV and BEV charging. Six more study cases are analyzed for FCR, aFRR and day-ahead market in which the penetration of households with HBESS in the networks is $18 \%$ and $36 \%$. This penetration is equal to $50 \%$ and $100 \%$ of a projection of the average penetration of households with PV in the operating area of Enexis in the Netherlands in the year 2025. The HBESS utilized in this paper have a capacity of $13.5 \mathrm{kWh}$ and a maximimum output power of $5 \mathrm{~kW}$.

In each study case $36 \%$ of the households have PV with a peak power of $3 \mathrm{~kW}$. For HDLG days a generation profile of a cloudy day in December is used, while for LDHG days a profile of a sunny day in June is used [9].

The demand of households is equal to the sum of the demand of BEV charging and domestic demand. A share of $13 \%$ of the households has a BEV which charges with a power of $11 \mathrm{~kW}$. With an average energy consumption of $10 \mathrm{kWh} /$ day [10], [11], the the charging time is approximately 1hour. Due to the low simultaneity factor of $\mathrm{BEV}$, the charging behavior is individually modeled as described by [12]. The domestic demand profile of households is derived from empirical data provided by NEDU [13].

\section{B. Market and energy price data}

To model the markets, actual market data of HDLG and LDHG days is used. For FCR, 15-minute averaged frequency signals of a HDLG day in December 2016 and a LDHG day in June 2017 in the Netherlands are used [14]. The reserved HBESS power capacity for FCR is $80 \%$.

For aFRR, prices of a HDLG day in December 2016 and a LDHG day in June 2017 in the Netherlands are used [14]. For the day-ahead market, market prices of the German EEX are utilized to determine the behavior of HBESS with volatile market prices [15]. The prices on the German EEX are relatively volatile due to the high penetration of renewable energy resources in Germany. Day-ahead market prices of a HDLG day in December 2016 and a LDHG day in June 2017 are used. The consumer energy prices $C$ are flat-rate 


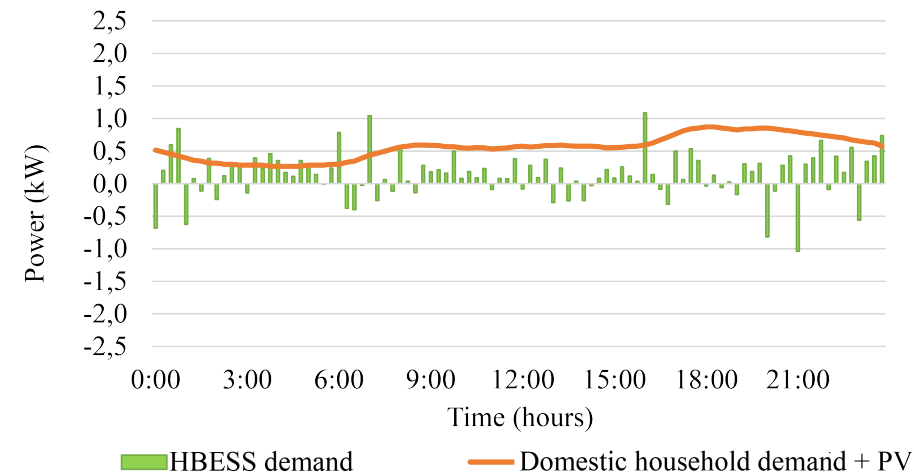

Fig. 1. Profiles of HBESS utilized for FCR and household domestic demand including PV on HDLG day. Negative power is injection into the grid.

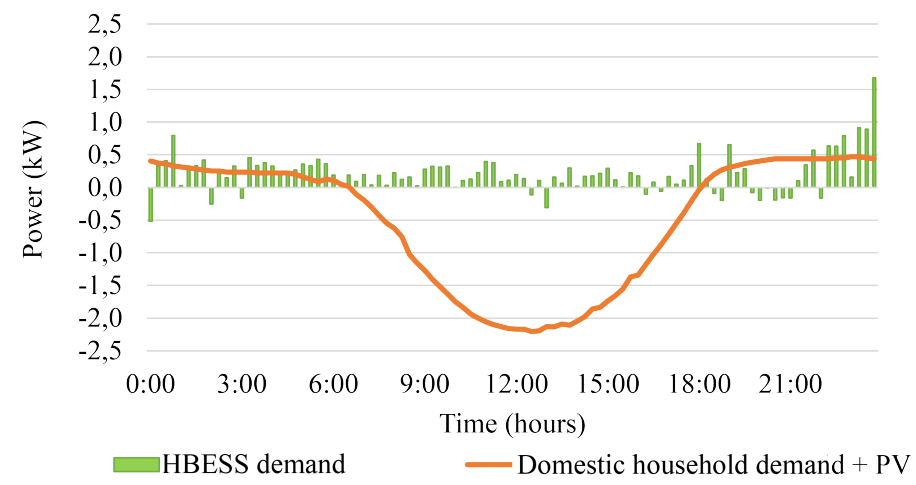

Fig. 2. Profiles of HBESS utilized for FCR and household domestic demand including PV on LDHG day. Negative power is injection into the grid.

at $0.20 € / \mathrm{kWh}$, the supplier share of the consumer energy price $C_{E}$ is $0.05 € / \mathrm{kWh}$, the feed-in tariff $F$ is $0.11 € / \mathrm{kWh}$ and the cost of the unidirectional losses $l$ are assumed to be $0.01 € / \mathrm{kWh}$.

\section{Results}

\section{A. HBESS profiles}

1) FCR: Figures 1 and 2 show the HBESS FCR (dis)charging profile and the household domestic demand profile including PV generation on HDLG and LDHG days. Although frequency deviation on the HDLG and LDHG days are relatively large, the output power of the HBESS is small compared to the reserved power capacity. The maximum power injection and absorption are $1 \mathrm{~kW}$ and $1.7 \mathrm{~kW}$ with a reserved capacity of $4 \mathrm{~kW}$. However the total household demand is still significantly changed by the HBESS. On the HDLG day the HBESS power is larger than the domestic household demand on some time instances. On the LDHG day the total household demand profile is mainly determined by the output of PV between 09:00h and 18:00h. However, during the rest of the day the HBESS does significantly impact the total household demand profile.

2) aFRR: Figures 3 and 4 show the HBESS aFRR (dis)charging profile and the household domestic demand profile including PV generation on HDLG and LDHG days.

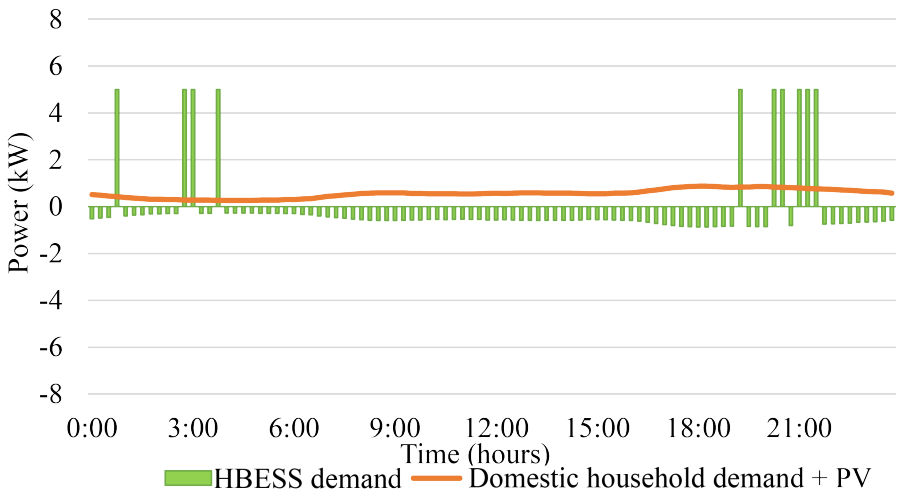

Fig. 3. Profiles of HBESS utilized for aFRR and household domestic demand including PV on HDLG day. Negative power is injection into the grid.

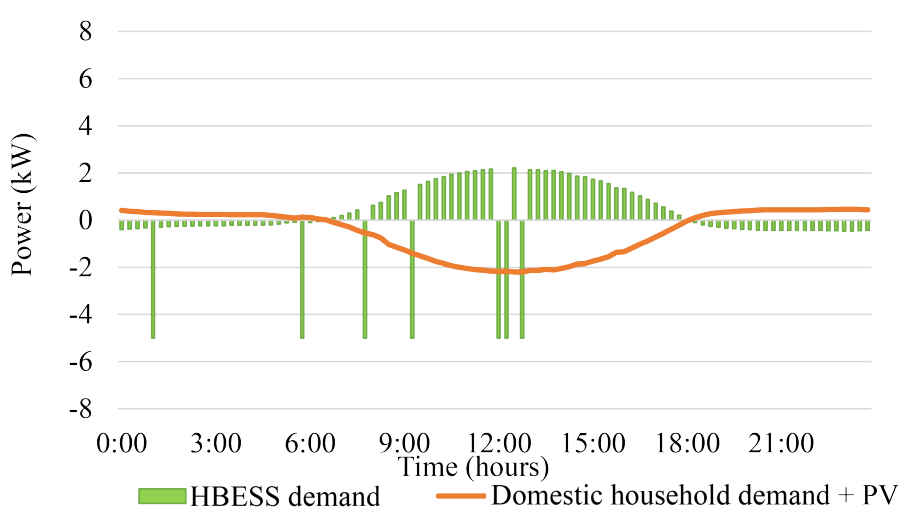

Fig. 4. Profiles of HBESS utilized for aFRR and household domestic demand including PV on LDHG day. Negative power is injection into the grid.

The absorption of PV generation is clearly visible between 08:00h and 18:00h during the LDHG day. During both days, peaks of 5 and $-5 \mathrm{~kW}$ can be observed which correspond to the time intervals in which the HBESS trades on the aFRR. For LDHG, these are the time intervals with the highest prices and for HDLG these are the time intervals with the lowest prices. As can be seen in the figures, the highest and lowest prices are during the peak generation and peak demand time intervals respectively. This indicates that the HBESS increases the power flow in the network during these intervals. The total household demand has a magnitude of up to approximately 6 and $-7 \mathrm{~kW}$ caused mainly by the HBESS.

3) Day-Ahead: Figures 5 and 6 show the HBESS day-ahead (dis)charging profile and the household domestic demand profile including PV generation on HDLG and LDHG days. The HBESS profile for the HDLG day shows three blocks of one hour with low prices in which the BESS charge. The rest of the day the BESS discharge to supply household demand. During the LDHG day the day ahead market price did not become high enough during the peak generation to cause the HBESS to discharge. The HBESS is charged by PV generation until the maximum state of charge is reached. When the total household demand becomes positive, the HBESS discharges to supply the household demand. During the HDLG day the 


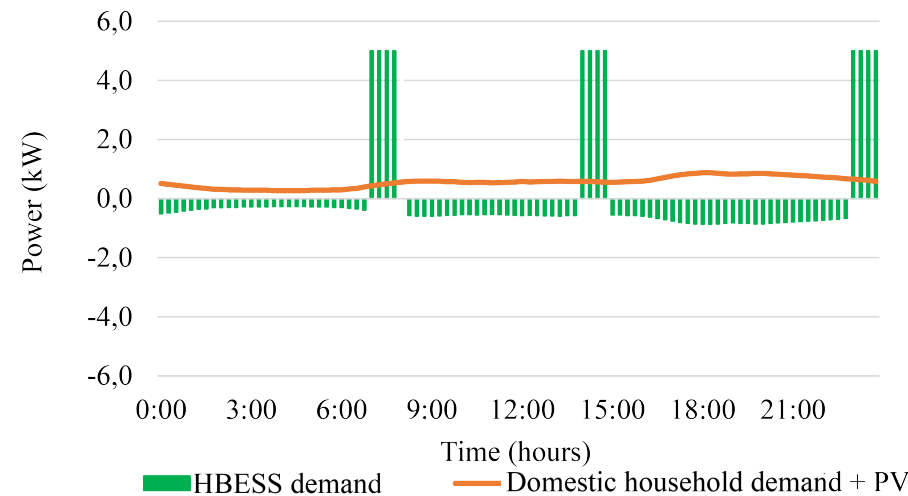

Fig. 5. Profiles of HBESS trading on the day-ahead market and household domestic demand including PV on HDLG day. Negative power is injection into the grid.

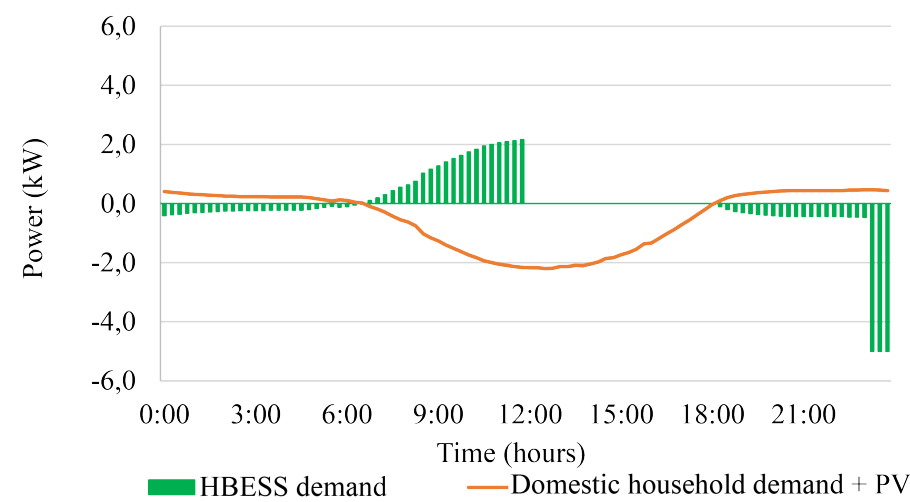

Fig. 6. Profiles of HBESS trading on the day-ahead market and household domestic demand including PV on LDHG day. Negative power is injection into the grid.

maximum household demand is significantly increased by the HBESS.

\section{B. Network loading and voltage magnitude}

The overloading and voltage problems in each study case and network are shown in table I. The problems are categorized into moderate and heavy problems. Moderate problems are the overloading of a component for $20 \%$ or less, or a voltage deviation of $5 \%$ to $10 \%$. These problems are usually acceptable for some small periods of time. Heavy problems are overloading of more than $20 \%$ and voltage deviations larger than $10 \%$. These problems should be avoided, since the overloading can rapidly deteriorate network components and the voltage is outside the boundaries specified by the IEC 50160 [16].

In the base study case, loadflow calculations are performed without HBESS in the network to provide a baseline for the loading and voltage problems in the network. As shown in table I some cable overloading and voltage problems occur during the base study case. These problems occur since the networks are originally not designed for households with PV and BEVs.
With the assumed penetrations of HBESS, PV and BEV in the study cases, more and heavier problems occur during the HDLG day than during the LDHG day. Transformer overloading problems do not occur in the base or FCR study cases. Cable overloading occurs in study cases with HBESS utilized for FCR, aFFR and trading on the day-ahead market. Most cable overloading issues occur in the dense urban network on a HDLG day. Over all networks, aFFR causes the most and heaviest cable overloading problems. Voltage magnitude problems in dense urban and rural networks already occur in the base study case, however HBESS increases the voltage deviation from nominal in the study cases.

Of the treated applications, HBESS utilized for aFRR causes the most network problems in the study cases. The transformer loading, cable loading and voltage deviation in the aFRR study case with a HBESS penetration of $36 \%$ is shown in tabel II. This gives an indications for the worst-case impact of HBESS on the networks, the required network upgrades and the upgrade costs. The results show that HBESS utilized for aFRR has a significant impact on the problems in the network and the required network upgrades. With HBESS the maximum transformer and cable loading in the networks increase significantly. The largest overloading problems occur in the dense urban network, while the largest voltage problems occur in the rural network. Transformer upgrades are required in dense urban and semi-urban networks, while cable upgrades are required in all networks. The total network upgrade costs are highest in the dense urban network, however the network upgrade costs per household are highest in the rural network followed by the dense urban network.

\section{Discussion}

The methodology described in section II is used to generate HBESS (dis)charging profiles for FCR, aFRR and the dayahead market on HDLG and LDHG days in the study cases described in section III. The analyses based on two worstcase days with the largest top-down power flow (HDLG) and the largest bottom-up power flow (LDHG) is very relevant for DNOs to design the distribution network. A limitation of the presented results is that in each scenario, all HBESS are active on the same market to determine the impact of the different markets individually. In practice, BESS in the same network might be active on different markets which could lead to a smaller impact of HBESS on the network by decreasing the simultaneity. Future research should indicate the probability of the occurrence of HBESS trading on the same market during LDHG and HDLG days.

An additional limitation of this research is the assumption of domestic household demand, PV generation and market prices for the modeling of the HBESS (dis)charge profiles. To improve the generation of the HBESS profiles, the uncertainty of these factors should be taken into account in future research to produce probabilistic HBESS (dis)charging profiles.

To reduce household modeling complexity, average profiles for domestic household demand and PV generation are utilized. This also enables direct comparison between different 
TABLE I

TYPE OF PROBLEMS IN STUDY CASES PER NETWORK. T: TRANSFORMER OVERLOADING, C: CABLE OVERLOADING, V: VOLTAGE MAGNITUDE PROBLEM. $\mathrm{M}: 1 \mathrm{pu}<$ LOADING $<1.2 \mathrm{pu}, 1.05 \mathrm{pu}<$ VOLTAGE $<1.1 \mathrm{pu}$ OR $0.9 \mathrm{pu}<$ VOLTAGE $<0.95 \mathrm{pu}$. H: LOADING $>1.2 \mathrm{pu}$ OR $1.1 \mathrm{pu}<$ VOLTAGE $<0.9 \mathrm{pu}$.

\begin{tabular}{|c|c|c|c|c|c|c|c|c|c|c|c|c|c|c|c|c|c|c|c|c|c|c|c|c|}
\hline \multirow[t]{2}{*}{$\begin{array}{l}\text { Study case (HBESS } \\
\text { penetration) }\end{array}$} & \multicolumn{6}{|c|}{ Dense urban } & \multicolumn{6}{|c|}{ Urban } & & \multicolumn{5}{|c|}{ Semi-urban } & \multicolumn{6}{|c|}{ Rural } \\
\hline & $\mathrm{T}$ & $\mathrm{C}$ & $\mathrm{V}$ & $\mathrm{T}$ & $\mathrm{C}$ & $\mathrm{V}$ & $\mathrm{T}$ & $\mathrm{C}$ & $\mathrm{V}$ & $\mathrm{T}$ & $\mathrm{C}$ & $\mathrm{V}$ & $\mathrm{T}$ & $\mathrm{C}$ & $\mathrm{V}$ & $\mathrm{T}$ & $\mathrm{C}$ & $\mathrm{V}$ & $\mathrm{T}$ & $\mathrm{C}$ & $\mathrm{V}$ & $\mathrm{T}$ & C & $\mathrm{V}$ \\
\hline Base $(0 \%)$ & - & - & - & - & $\mathrm{H}$ & $\mathrm{M}$ & - & - & - & - & - & - & - & 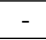 & - & - & - & - & - & - & $\mathrm{H}$ & - & - & $\mathrm{H}$ \\
\hline FCR & - & - & - & - & $\mathrm{H}$ & $\mathrm{N}$ & - & 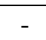 & - & - & - & - & & 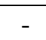 & 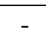 & 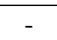 & - & - & - & - & $\mathrm{H}$ & - & - & $\mathrm{H}$ \\
\hline FCR $(36 \%)$ & - & $\mathrm{M}$ & $\mathrm{M}$ & - & $\mathrm{H}$ & $\mathrm{M}$ & - & - & - & - & - & - & . & - & - & - & - & - & - & - & $\mathrm{H}$ & - & - & $\mathrm{H}$ \\
\hline $\mathrm{aFR}$ & - & $\mathrm{M}$ & $\mathrm{N}$ & $\mathrm{H}$ & $\mathrm{H}$ & $\mathrm{H}$ & - & - & - & - & - & 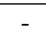 & & - & 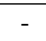 & - & M & $\mathrm{M}$ & - & - & $\mathrm{H}$ & - & - & $\mathrm{H}$ \\
\hline aFRR & $\Pi$ & $\mathrm{H}$ & $\mathrm{H}$ & $\mathrm{H}$ & $\mathrm{H}$ & $\mathrm{H}$ & - & $\mathrm{M}$ & - & - & $\mathrm{H}$ & $\mathbb{N 1}$ & 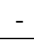 & $\mathrm{M}$ & $\mathrm{M}$ & $\mathrm{H}$ & $\mathrm{H}$ & $\mathrm{H}$ & - & - & $\mathrm{H}$ & - & - & $\mathrm{H}$ \\
\hline Day-ahead ( & - & - & - & M & $\mathrm{H}$ & $\mathrm{H}$ & - & - & - & 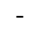 & - & - & - & - & - & - & - & M & - & - & $\mathrm{H}$ & - & - & $\mathrm{H}$ \\
\hline Day-ahead (36\%) & - & $\mathrm{M}$ & $\mathrm{M}$ & $\mathrm{H}$ & $\mathrm{H}$ & $\mathrm{H}$ & 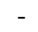 & - & - & & $\mathrm{M}$ & $\mathrm{M}$ & & - & - & $\mathrm{M}$ & $\mathrm{H}$ & $\mathrm{M}$ & - & - & $\mathrm{H}$ & - & - & $\mathrm{H}$ \\
\hline
\end{tabular}

TABLE II

NETWORK PROBLEMS, REQUIRED NETWORK UPGRADES AND COSTS IN THE BASE AND AFRR (36\%) STUDY CASES. HH:HOUSEHOLD.

\begin{tabular}{lcccc}
\hline Property & $\begin{array}{c}\text { Dense } \\
\text { urban }\end{array}$ & Urban & Semi-urban & Rural \\
\hline $\begin{array}{l}\text { Maximum transformer } \\
\text { loading (base/aFRR,\%) } \\
\text { Maximum cable }\end{array}$ & $72 / 176$ & $32 / 97$ & $42 / 121$ & $35 / 96$ \\
$\begin{array}{l}\text { loading (base/aFRR,\%) } \\
\text { Maximum voltage } \\
\text { deviaton (base/aFRR,\%) }\end{array}$ & $730 / 248$ & $44 / 134$ & $54 / 133$ & $38 / 38$ \\
\hline $\begin{array}{l}\text { Required cable upgrade } \\
\text { length (base/aFRR,\%) }\end{array}$ & $6 / 32$ & $3 / 7$ & $4 / 11$ & $23 / 23$ \\
$\begin{array}{l}\text { Required transformer } \\
\text { upgrades (base/aFRR,\%) }\end{array}$ & $0 / 29$ & $0 / 0$ & $0 / 14$ & $0 / 0$ \\
\hline $\begin{array}{l}\text { Total upgrade cost } \\
\text { (base/aFRR,€ per HH) }\end{array}$ & $24 / 175$ & $0 / 28$ & $0 / 157$ & $471 / 471$ \\
\hline
\end{tabular}

scenarios to determine the impact of HBESS. However, in practice each household will have a different demand profile. Individual household modeling produces more accurate results which can be analyzed in future research.

The conducted research has valuable implications. The combination of modeling (dis)charge profiles of BESS utilized for increasing self-consumption combined with FCR, aFRR and trading on the day-ahead market, and its impact on LV networks is not yet described in literature. The business case for trading with BESS will become more positive in the future due to higher price volatilities on electricity markets and decreasing HBESS prices [17].

\section{CONCLusions}

This paper presents a method requiring minimal input parameters which enables DNOs to analyze network planning scenarios with HBESS utilized for FCR, aFRR and trading on the day ahead-market in LV networks. Study cases of four real networks in the Netherlands show that HBESS can cause both overloading and voltage problems in the networks which requires sizable cable and transformer upgrades to mitigate. The presented method enables DNOs to analyze and prepare for scenarios where HBESS are utilized for multiple applications by determining the critical parts of LV networks. Without this analysis, unexpected network congestion will occur when HBESS are utilized for the described applications.
As demonstrated in the study cases, the analysis of the required network upgrade costs from the results is straightforward. Extension to other analysis such as optimal upgrade scheduling can also be easily implemented.

\section{REFERENCES}

[1] N. D. Hatziargyriou, D. Škrlec, T. Capuder, P. S. Georgilakis, and M. Zidar, "Review of energy storage allocation in power distribution networks: applications, methods and future research," IET Generation, Transmission \& Distribution, vol. 10, no. 3, pp. 645-652, 2016.

[2] J. Eyer and G. Corey, "Energy Storage for the Electricity Grid : Benefits and Market Potential Assessment Guide," vol. 321, no. February, 2010.

[3] Movares, "De waarde van flexibel laden," Tech. Rep., 2016.

[4] Z. Wang, C. Gu, F. Li, P. Bale, and H. Sun, "Active demand response using shared energy storage for household energy management," IEEE Transactions on Smart Grid, vol. 4, no. 4, pp. 1888-1897, 2013.

[5] C. Clastres, T. T. Ha Pham, F. Wurtz, and S. Bacha, "Ancillary services and optimal household energy management with photovoltaic production," Energy, vol. 35, no. 1, pp. 55-64, 2009. [Online]. Available: http://dx.doi.org/10.1016/j.energy.2009.08.025

[6] Phase to Phase, "Vision Network Analysis," 2018. [Online]. Available: https://phasetophase.nl/vision-network-analysis.html

[7] J. Mehmedalic, J. Rasmussen, and S. Harbo, "Grid Impact studies of electric vehicles ; Reinforcement Costs in Low-voltage Grids," European commission, Tech. Rep., 2013.

[8] M. van Lumig and S. Uytterhoeven, "Literatuurstudie naar meest voorkomende wijken en woningen," Laborelec, Tech. Rep., 2009.

[9] G. B. Litjens, E. Worrell, and W. G. van Sark, "Influence of demand patterns on the optimal orientation of photovoltaic systems," Solar Energy, vol. 155, pp. 1002-1014, 2017. [Online]. Available: https://doi.org/10.1016/j.solener.2017.07.006

[10] T. W. Hoogvliet, G. B. M. A. Litjens, and W. G. J. H. M. van Sark, "Provision of regulating- and reserve power by electric vehicle owners in the Dutch market," Applied Energy, vol. 190, pp. 1008-1019, 2017.

[11] C. de Cauwer, D. Gillis, T. Coosemans, and J. van Mierlo, "Identification of EV use patterns, based on large scale EV monitoring data," World Electric Vehicle Journal, vol. 6, no. 1, pp. 1-11, 2013.

[12] R. A. Verzijlbergh, Z. Lukszo, E. Veldman, J. G. Slootweg, and M. Ilic, "Deriving electric vehicle charge profiles from driving statistics," Power and Energy Society General Meeting, 2011 IEEE, pp. 1-6, 2011.

[13] NEDU, "Verbruiksprofielen," 2018. [Online]. Available: http://www.nedu.nl/documenten/verbruiksprofielen/

[14] TenneT, "System and Transmission data," 2018. [Online]. Available: http://www.tennet.org/english/operational_management/export_data.aspx

[15] EEX, "European Energy Exchange,"' 2018. [Online]. Available: https://www.eex.com/de/

[16] Phase to Phase, "Spanningshuishouding," in Netten voor distributie van elektriciteit, 2nd ed., Arnhem, 2012, ch. 14.

[17] EASE/EERA, "European Energy Storage Technology Development Roadmap towards 2030," European Association for Storage of Energy and European Energy Research Alliance, Brussels, Tech. Rep., 2013. 